\title{
La creación del Instituto Santa Irene en Vigo y sus antecedentes (1842-1946)
}

\section{The Creation of Santa Irene High School in Vigo: A Background Study}

\author{
Miriam VARELA IGLESIAS \\ Escuela Univ. CEU de Magisterio de Vigo
}

\begin{abstract}
RESUMEN: Las reformas de la educación secundaria aprobadas bajo el Ministerio de Pidal en 1845 fueron de importancia fundamental, como sabemos, para el desarrollo de la moderna educación secundaria pública y urbana en España. Sin embargo, la ciudad de Vigo, a pesar de su notable expansión social a lo largo de la segunda mitad del siglo XIX, no dispondrá de dicho establecimiento docente hasta 1927, a pesar de los múltiples intentos locales para lograrlo. Casi veinte años después de 1927 la ciudad contará con un extraordinario edificio e instalaciones dedicadas a este Instituto, gracias al legado americano de Policarpo Sanz.
\end{abstract}

PALABRAS CLAVE: Educación secundaria- Institutos de Bachillerato- Currículum de estudios- Ciudad de Vigo.

ABSTRACT: The secondary school reforms approved during Pidal's Ministry in 1845 were essential for the development of modern, public secondary education in urban areas in Spain. However, despite the great social expansion of the city of Vigo during the second half of the 19th century and the local efforts made to achieve it, the city did not have an educational institution of this kind until 1927. Almost twenty years later, thanks to the American legacy of Policarpo Sanz, the city was finally able to build a magnificent building and facilities for this institution.

KEY WORDS: Secondary school, High school, Curriculum, city of Vigo.

\section{El plan Pidal de 1845 y la creación de los Institutos de Bachillerato}

Las reformas de la educación secundaria aprobadas bajo el Ministerio de Pidal en $1845^{2}$ fueron de importancia fundamental, como sabemos, para el desarrollo de la moderna educación secundaria pública y urbana en España. Sin embargo, la ciudad de Vigo, a pesar de su notable expansión social a lo largo de la segunda mitad del siglo XIX no

\footnotetext{
${ }^{1}$ Agradezco al profesor Dr. Antón Costa Rico, de la USC, la lectura y sugerencias recibidas previas a la edición de la presente contribución.

${ }^{2}$ Vid. Carmen García, Génesis del sistema educativo liberal en España. Del Informe Quintana a la Ley Moyano (1813-1857)(Oviedo: Servicio de Publics. De la Universidad,1994).
} 
contaría con dicho establecimiento docente hasta 1927, lo que no deja de ser llamativo y merecería la pena poder explicarlo. Es lo que nos proponemos.

La Educación Secundaria contemporánea, periodo en que nace y se consolida tal y como la conocemos actualmente, se vio acompañada de una serie de problemas, como fueron el de su denominación, su finalidad, la unicidad o diversidad de la misma, el contenido de sus estudios, su carácter cíclico o enciclopédico, la edad de ingreso y los requisitos de acceso, el papel de los exámenes, las relaciones entre la enseñanza pública (oficial) y la privada, la financiación o la formación de su profesorado ${ }^{3}$. Existen numerosos trabajos de investigación sobre la evolución de la Educación Secundaria en los que se tratan estos temas ${ }^{4}$.

Conviene señalar que hasta 1857 con la Ley Moyano, consecuencia del acuerdo entre moderados y progresistas, se sucedieron variedad de planes sobre dicha enseñanza. La Ley significó la consolidación del sistema educativo liberal y el comienzo de la estabilidad, sobre todo a nivel legislativo, de administración y del desarrollo de la instrucción pública durante más de un siglo. Las características fundamentales de esta ley eran su marcada concepción centralista de la instrucción, dado que se seguía el modelo francés como en todas las facetas de la Administración, el carácter ecléctico y moderado en la solución de las cuestiones más problemáticas, como eran la intervención de la Iglesia en la enseñanza o el peso de los contenidos científicos en la Segunda Enseñanza, la promoción legal y la consolidación de una enseñanza privada, básicamente católica, a nivel primario y secundario y, por último, la incorporación definitiva de los estudios técnicos y profesionales a la enseñanza postsecundaria. Era una ley que venía a consagrar un sistema educativo cuyas bases fundamentales se encontraban en el Reglamento de 1821, en el Plan del Duque de Rivas de 1836 y en el Plan Pidal de 1845 y que consagraba los principios del moderantismo histórico, a saber: gratuidad relativa para la enseñanza primaria, centralización, uniformidad, secularización, libertad de enseñanza limitada e intervencionismo eclesiástico.

Según lo dispuesto en el Plan Pidal ${ }^{5}$, confirmado por la Ley Moyano, los Institutos de Bachillerato se dividían en tres clases; de "primera clase", Madrid, de "segunda clase", en las capitales de provincia y pueblos con Universidad y de "tercera" en el resto de las poblaciones. Los estudios de bachillerato se dividían en: "estudios generales", y de "aplicación

\footnotetext{
${ }^{3}$ José Antonio Lorenzo "Evolución y problemática de la Educación Secundaria Contemporánea en España," en Revista Complutense de Educación (7, no 2, Madrid, 1996), 51-79.

${ }^{4}$ Algunos de estos trabajos son los de Antonio Viñao, Política y educación en los orígenes de la España Contemporánea (Madrid: Siglo XXI) 1982; Federico Sanz, La Segunda enseñanza oficial en el siglo XIX (Madrid: MEC), 1985; Gonzalo Menéndez-Pidal, La España del siglo XIX vista por sus contemporáneos, (Madrid: Centro de Estudios Constitucionales), 1988; Emilio Díaz e la Guardia, Evolución y desarrollo de la Enseñanza Media en España de 1875 a 1930. Un conflicto político-pedagógico (Madrid: CIDE), 1988.

${ }^{5}$ El Plan General de Estudios Pidal, conocido como "Plan Pidal", decretado por el Ministro de Gobernación Pedro José Pidal en septiembre de 1845, contemplaba que los establecimientos de enseñanza podían ser públicos o privados. Respecto a los establecimientos públicos establecía que los habría de primera clase o superiores, de segunda clase y de tercera, que serían establecidos en las provincias. La consolidación de los institutos se produjo en un periodo que podemos delimitar aproximadamente entre 1845 y 1868. El Plan Pidal estuvo vigente más de 20 años y fue revalidado por la Ley General de Instrucción Pública de 1857 (Ley Moyano).
} 
a las profesiones industriales". Los estudios generales durarían seis años distribuidos en dos períodos de cuatro y de dos años de duración. Incluían, además de Religión y Moral cristiana, las asignaturas de Latín, Castellano, Griego, Historia y Matemáticas, Ciencias y Física y Química, Elementos de Psicología y Lógica. Por su parte, los "estudios de aplicación se extendían, entre otras, a las materias de: Dibujo lineal y de figura, Nociones de agricultura y Aritmética mercantil.

Había dos tipos de títulos: Bachiller en Artes, si se aprobaban los seis cursos de los estudios generales y el examen de grado, y Certificado de Peritaje, en el caso de los "estudios de aplicación", El título de bachiller en Artes habilitaba a los alumnos a matricularse en la Universidad, según lo determinaba el artículo 23 de la Ley: "Terminados los estudios generales de segunda enseñanza y aprobados los seis cursos, los alumnos podrán realizar el grado de bachiller en Artes, que dará acceso a las Facultades". El Certificado de Peritaje, por su parte, habilitaba para el ingreso en las Escuelas superiores de Ingeniería y Bellas Artes.

Cada provincia tendría un Instituto que incluiría las dos orientaciones de estudio: los estudios generales y los de aplicación. La financiación correría a cargo de cada provincia, tanto del personal docente, como de los gastos de funcionamiento y de los derechos académicos que aportasen los alumnos. En las inmediaciones de los Institutos se establecerían colegios residenciales donde por una módica retribución se recibiría a los alumnos internos. A los alumnos que sobresaliesen en aplicación, progreso y conducta se les distribuirían anualmente premios como diplomas especiales, medallas y exención del pago de tasas. Las asignaturas se estudiarían en libros de texto que se elegirían de la lista que el Gobierno publicase cada tres años. Para establecer un colegio privado de Segunda Enseñanza se requería autorización del Gobierno y en este caso los estudios cursados en estos establecimientos tendrían validez académica siempre que los exámenes anuales se celebrasen en el Instituto al que estuviese adscrito el colegio. Por otra parte, se reconocía la enseñanza doméstica para la enseñanza primaria y para el primer ciclo de la Segunda Enseñanza. Respecto al profesorado ${ }^{6}$, se determinaba que ningún profesor de establecimiento público podía enseñar en establecimiento privado ni dar lecciones particulares sin expresa autorización del Gobierno.

Posteriormente a la Ley Moyano, el plan de 1868 (Ruíz Zorrilla) introdujo una cierta renovación ya que ofrecía a los alumnos dos opciones, una con latín, que era la habitual, y

\footnotetext{
${ }^{6}$ Se consideraban catedráticos de Instituto a los que impartían tanto los "estudios generales", como los "estudios de aplicación". Para aspirar a las cátedras de Instituto se requería estar en posesión del título de bachiller en la facultad a que correspondía la asignatura. Si se trataba de cátedras de enseñanzas de aplicación se determinaba para qué asignaturas se había de exigir el mismo grado de bachiller anterior y para cuáles el título profesional de la carrera a que correspondían los respectivos estudios. Para ser catedrático en los centros de enseñanza profesional (de veterinaria, de profesores mercantiles, de maestros de obra, de aparejadores, de maestros de primera enseñanza) se exigía el título de licenciado. Los profesores de Lenguas vivas y Dibujo, y los de Música no necesitaban título. Cada Instituto, Escuela superior o profesional, tendría un director nombrado por el Gobierno, que podría recaer en un profesor del establecimiento. El director del Instituto estaría bajo las órdenes del Rector del distrito universitario.
} 
otra sin latín, más renovadora. Las novedades apuntaban a dos objetivos claros; adecuar las enseñanzas a las exigencias de conocimiento aplicado de la vida moderna y formar ciudadanos en el sentido reclamado por la burguesía. El objetivo debía de ser el dotar a los estudiantes de unos conocimientos específicos para que cuando terminasen el Bachillerato estuvieran en condiciones de elegir con seguridad sus estudios universitarios. Años más tarde en 1899 hubo un intento de ampliar la secundaria a siete años, pero no duró más de un año, ya que a partir de 1900 se volvió a seis años de escolaridad.

Viene al caso poner de relieve que desde los primeros momentos de la existencia de la Educación Secundaria había dos tendencias contrapuestas, una educación secundaria humanística y teórica, más academicista y tradicional, y otra que ponía el acento en los aspectos científico naturales y en la que se empezaba a prestar atención a una clara orientación técnico-profesional. Se incluían aquí asignaturas como Ciencias Naturales, Química, Física, Matemáticas e Idiomas modernos. De este modo, según el momento político, se le daba más importancia a unas asignaturas o a otras. Con los diferentes relevos de gobierno, en los que con frecuencia se implantaba un nuevo plan o al menos uno reformado, aumentaba o disminuía el número de horas lectivas de las asignaturas de cada tendencia. Así, en 1898 el ministro Gamazo ofrecía varias posibilidades de elección intentando combinar humanismo y utilitarismo, lenguas vivas y lenguas clásicas, bachillerato literario y científico ${ }^{7}$. Sin embargo, en 1899 el latín se extendía a seis de los siete cursos de bachillerato, que en el anterior plan había quedado reducido a tres. En 1903 se elaboró otro plan que denominaba a estos centros como Institutos Generales y Técnicos, pretendiendo que en los Institutos se impartieran enseñanzas de Agricultura, Comercio y Magisterio, además del Bachillerato General, lo que tuvo a su vez en este caso limitada presencia. Se establecía un Bachiller único con una duración de seis años.

\section{Vigo, sin centro público de educación secundaria hasta 1873}

El instituto de bachillerato Santa Irene de Vigo es el primero que se fundó en la ciudad tras una larga lucha que tuvo su origen en 1842, cuando cerró sus puertas el Colegio de Humanidades, lo que supuso que la villa se quedase sin un centro oficial donde cursar la segunda enseñanza. Tras varios intentos infructuosos, el instituto, sin embargo, no se fundó definitivamente hasta 1927, aunque hay que señalar que anteriormente, en 1873, existió un instituto solo durante un año escolar, viéndose obligado a cerrar sus puertas, entre otras cuestiones, por problemas económicos.

Las diferentes medidas de desamortización emprendidas por los gobiernos liberales y el cierre obligado de los colegios de Gramática y de Humanidades, desmantelaron el conjunto de instituciones educativas que impartían conocimientos pertenecientes al ciclo de la tradicional educación secundaria. En 1842 se pretendió declarar al Colegio de Humanidades de Vigo, Instituto Superior de Provincia en una Junta celebrada por los profesores

${ }^{7}$ Olegario Negrín, "Algunas características de la enseñanza secundaria española decimonónica a través de la legislación", en Historia de la Educación. Revista Interuniversitaria (num. 2, 1983), 275-286. 
del Colegio, pero esta primera intención de crear el instituto, transformando el Colegio de Humanidades, no fue posible llevarla a cabo. Durante los siguientes años se sucedieron varios hechos que dejaron patente la necesidad y la intención de fundarlo en varias ocasiones. El carecer de un centro oficial en el que se impartiera la Segunda Enseñanza, como en el caso de otras ciudades gallegas ${ }^{8}$, obligaba a las familias de alto poder adquisitivo a enviar sus hijos a centros privados de la propia ciudad, entre los creados en las últimas décadas del siglo XIX o también en este momento al de los Jesuitas de Camposancos (A Guarda). Algunas familias optaban, por su parte, por enviar a sus hijos a lejanos colegios como El Escorial, y muchos de los catalanes afincados en Vigo, los mandaron a sus tierras de origen ${ }^{9}, 0$ en casos a Inglaterra.

Fue en 1869 cuando por primera vez se solicitó por un particular la creación de un Colegio de Segunda Enseñanza para carreras especiales como Comercio, Náutica y Lenguas vivas, en un documento dirigido al Ayuntamiento. Sobre esta noticia no disponemos de más datos, aunque por los acontecimientos, podemos decir que la iniciativa no prosperó. La dificultad por parte de la municipalidad para crear el instituto hizo que personalidades de la talla de Antonio López de Neira ${ }^{10}$, Manuel Bárcena, Juan Tapias Ferrer ${ }^{11}$. Antonio Conde González, Solleiro Negrete, Fernández de la Cigoña ${ }^{12}$ Juan Garcí y Roig, Victoriano Martínez de la Escalera y Tomás Vicetto y otros, solicitasen un empréstito para poder llevar a cabo el proyecto el 19 de febrero de $1870^{13}$, reuniéndose en su calidad de mayores contribuyentes en la Casa Consistorial, para deliberar con el Ayuntamiento acerca de las bases y condiciones de la "contratación del empréstito acordado para establecer un Colegio de Segunda Enseñanza en la ciudad".

Se consideraba que el instituto proporcionaría "una instrucción sólida y en consonancia con la época liberal que alcanzamos", aunque se carecía de fondos para su instalación, por lo que se solicitaba un empréstito ${ }^{14}$. Se creó una comisión de Hacienda para elaborar un informe razonado sobre la necesidad y conveniencia de establecer el Colegio de Se-

\footnotetext{
${ }^{8}$ El establecido en Pontevedra existía desde 1845, igual que los de Santiago y de Ourense que son de la misma época, aunque fue el Instituto Público de Enseñanza Secundaria de Lugo, el primero de Galicia fundado en 1844. En 1837 se formó en la Diputación de Lugo una comisión de estudio para la instalación de un instituto en la ciudad, pero no será hasta el 26 de marzo de 1842 cuando se realiza la petición oficial al gobierno de instalación de un Instituto en Lugo, respondiendo a una propuesta de los progresistas lucenses. En 1848 sería trasladado a Monforte, donde permaneció hasta 1862, en que volvió a Lugo. Vid. Antonio Prado, La Diputación Provincial y los inicios de la instrucción pública en Lugo (Lugo: Servizo de Publicacións da Deputación), 1990 e Antón Costa, Historia da Educación e da Cultura en Galicia. (Séculos IV-XX), (Vigo: Edicións Xerais de Galicia, 2004), 766-777. ${ }^{9}$ Bonanova de los Hermanos La Salle o el Centro de Estudios de la Compañía de Jesús en Barcelona fueron testigos de la educación superior de vigueses como: Massó, Yánez, un hijo de Tomás Mirambell Maristan y Pedro Sensat Curbera.

${ }^{10}$ Alcalde de Vigo de 1897 a 1901.

${ }^{11}$ Antiguo alumno del Colegio de Humanidades de la ciudad

${ }^{12}$ Comerciante y miembro de la corporación viguesa en el reinado de Isabel II.

${ }^{13}$ Archivo Municipal de Vigo (en adelante A. M. V.), Sección. "Educación”, Leg. 9, Carp. 26.

${ }^{14}$ Un empréstito de 24.000 escudos y se venderían mil doscientas acciones de veinte escudos cada una, para que todas las fortunas tomen parte en él y amortizable en diez años por décimas partes consignando al efecto en sus presupuestos las cantidades precisas para amortización e intereses de tres por ciento que devengarán.
} 
gunda Enseñanza con estas características; el informe se presentó el 8 de enero de 1870 y lo firmaron: Ricardo Solleiro ${ }^{15}$, José Ramón Curbera, Delmiro Tapias Ferrer, y Juan Buch ${ }^{16}$. Aceptado en principio el proyecto, se llevó a estudio. En este informe se explicaban las materias que se impartirían:

En este colegio se darán las materias del cuadro oficial hasta el Bachillerato en Artes, inclusive con clases para la Primera Enseñanza Elemental y Superior, y para Náutica, Comercio y Lenguas vivas. ${ }^{17}$

Dicha Comisión suscitó además la necesidad de incorporar a la Junta de Instrucción Pública (que fue la iniciadora del pensamiento) y de convocar y oír el ilustrado parecer de varios vecinos del pueblo, por su posición social e ilustración, conforme a lo acordado por la municipalidad en la sesión del 9 de diciembre de 1869, en la que se habían establecido los medios necesarios para llevar el proyecto a cabo. El 7 de enero de 1870 quedó sobre la mesa este informe de la Comisión de Hacienda, que se había iniciado el año anterior. Se dieron los pasos necesarios para gestionar el empréstito, pero estas gestiones no dieron fruto, por lo que de nuevo en diciembre de 1871 se retomaron los acuerdos para la creación del centro y algunos profesores al conocer la noticia, se ofrecieron como profesores del futuro colegio. El 4 de enero de 1872 el alcalde informaba, según se recoge en el libro de actas correspondiente, que se habían reunido 10.750 pesetas. Esta iniciativa tampoco prosperó y año y medio más tarde hubo un definitivo intento en el que se decidió apoyar la petición de Ramón Hermida Romero, director de un colegio de Primera Enseñanza, que pretendía crear el Instituto. El proyecto fue aceptado y consensuado por unanimidad en la ciudad y el Rector de la Universidad Literaria de Santiago, Antonio Casares, concedió su beneplácito. El mismo día 20 de aquel mes, daba a conocer su autorización al Ayuntamiento, pues se consideraba un proyecto imprescindible para Vigo: “... por su población, por su situación topográfica y por sus intereses es el principal pueblo de la provincia y lleva ventajas considerables sobre Pontevedra y Tuy; carece sin embargo de los elementos de instrucción que estas ciudades tienen para la segunda enseñanza..."18.

La ciudad en aquel momento, solo contaba con escuelas de primaria como cualquier Ayuntamiento rural, lo que era una gran vergüenza para Vigo ${ }^{19}$. Se sugería formar un presupuesto extraordinario para la fundación del centro que entrase en los presupuestos del año, pues la cantidad de 8.000 escudos no era suficiente para los gastos de instalación y sueldos de profesorado en el primer año. La Comisión por tanto, después de meditarlo, concibió la idea de levantar de nuevo el empréstito municipal como se había pensado en 1870, con el fin de instalar y comenzar así el funcionamiento del establecimiento.

En el documento de la comisión se añadía: “...las diputaciones provinciales y los ayuntamientos han sido autorizados y hasta estimulados por el gobierno supremo para fundar

\footnotetext{
${ }^{15}$ Presidente de la Junta local de Instrucción Primaria y prestigioso docente.

${ }^{16} \mathrm{La}$ familia de Buch fueron importantes empresarios de origen catalán en la ciudad. Juan Buch fue propietario de una fábrica de pesca establecida en el litoral vigués. Álvaro Cunqueiro y José María Álvarez (coords.), Vigo en su historia (Vigo: Caja de Ahorros Municipal de Vigo, 1980), 343.

${ }^{17}$ A. M. V. Sección. "Educación", Leg. 9, Carp. 26.

${ }^{18}$ A.M.V. Educación. Leg. 9. Carp. 25. Informe de la necesidad de este colegio para la ciudad.

${ }^{19}$ Ibíd.
} 
y sostener toda clase de establecimientos de enseñanza..." y por ello se pedía que una comisión del seno de la corporación municipal, presidida por el alcalde se asociase a los doce vecinos mayores accionistas en "...el empréstito a fin de que tengan a su cargo el régimen económico, administrativo y literario del establecimiento..." ${ }^{20}$.

\section{Por fin, el Instituto, pero de corta duración}

Finalmente, se fundó el Instituto libre de Segunda Enseñanza en 1873, transformando el Colegio de Primera y Segunda Enseñanza que ya existía a cargo de Ramón Hermida y Romero ${ }^{21}$.

Las condiciones para los alumnos eran las siguientes: los que concurriesen deberían pagar de matrícula 150 pesetas en dos plazos ${ }^{22}$ y el importe, que debía recibir el Ayuntamiento, lo cobraría el director que se obligaba a pagar el edificio, los profesores, los bedeles, los empleados de la secretaría y se ocuparía también de dotar de todo el material necesario para la enseñanza, como gabinetes de Geografía, Historia Natural, Física y Química, sin que el Ayuntamiento tuviese que hacer otros sacrificios además de pagar anualmente y por mensualidades la cantidad de 3.000 pesetas como subvención al colegio. Como consecuencia de la fundación acordada y de la subvención que recibió el establecimiento, el Ayuntamiento se reservó ejercer en él la conveniente vigilancia por medio de una comisión especial a fin de asegurarse de que se daba la enseñanza según lo exigían las disposiciones vigentes en aquel tiempo y la utilidad y conveniencia del vecindario. Así fue como el 13 de septiembre de 1873 quedó acordada finalmente, la fundación el Instituto ${ }^{23 .}$

Estaba situado en el mismo local que había ocupado 31 años antes el Colegio de Humanidades, y para su correcto funcionamiento se constituyó una comisión inspectora del centro formada por concejales y padres de alumnos; entre éstos figuraban personas relevantes de la ciudad y vinculadas anteriormente con este proyecto, como Antonio Conde Domínguez, Francisco Solleiro Negrete y César Rodríguez Sanmartín ${ }^{24}$. De todos modos, el centro tuvo problemas de escasez de mobiliario y otro material necesario, ya que en un artículo publicado en Faro de Vigo se decía que el director se lamentaba a todas horas de la falta de recursos para la compra de útiles ${ }^{25}$.

\footnotetext{
${ }^{20}$ lbíd.

${ }^{21}$ A.M.V., Educación. Leg 9. Carp. 13. Fue director hasta el 30 de septiembre de 1874. Se especifica que lo fue hasta la supresión de los establecimientos de esta clase acordada por Orden General del Gobierno.

${ }^{22}$ Cinco pesetas por derechos de exámenes y 25 pesetas por los de grados, cuyos derechos se repartirían proporcionalmente entre los profesores según la ley.

${ }^{23}$ En La Concordia de 3/10/1873 se habla de la inauguración.

${ }^{24}$ A.M.V., Libro PLE 101, de sesiones plenarias municipales, acuerdo adoptado 30/10/1873. Antonio Conde Domínguez pertenecía a una tradicional familia de consignatarios en la ciudad. Solleiro Negrete era gaditano, importante industrial y agricultor que figuró entre los promotores también del tranvía a Baiona, y César Rodríguez Sanmartín era teniente de navío.

${ }^{25}$ Faro de Vigo (4/08/1879), "Sección Editorial: Todo por Galicia".
} 
La apertura oficial tuvo lugar el 1 de octubre de 1873 en la casa grande de A Laxe. Se invitó a los ciudadanos y concejales a asistir a dicho acto solemne y José Ramón Curbera Puig presidió el acto como primer teniente alcalde. Todo estaba dispuesto para aquel día, excepto algunas colecciones adquiridas para los gabinetes del establecimiento, que según el diario La Concordia no habían podido llegar a destino por la mala situación de las vías de comunicación ${ }^{26}$. Se elogiaba a Ramón Hermida, el director, porque "...no se dedicaba exclusivamente a la segunda enseñanza, sino también a la Escuela de Comercio, Partida doble, Lengua Inglesa y Francesa, Dibujo, Música, Piano y Gimnasia"27.

Los profesores que darían las clase ${ }^{28}$ serían Telmo Rotea, doctor en Filosofía y Letras que explicaría la asignatura de $1^{\circ}$ y $2^{\circ}$ año de Latín y Psicología, Lógica y Ética y sería también secretario del centro; Ramón Hermida, profesor de Ciencias Exactas, Físicas y Naturales daría Aritmética, Álgebra, Geometría y Trigonometría ${ }^{29}$ José Rodal, licenciado en derecho impartiría Historia Universal y de España; José Carvajal y Pereira ${ }^{30}$, doctor en Derecho, daría Geografía, Retórica y Poética; Antonio Novas, doctor en Medicina y cirugía y licenciado en Farmacia, daría Historia Natural, Fisiología e Higiene; Rodrigo Rodríguez, licenciado también en Farmacia, daría Física y Química. Además impartirían clase Jacobo Domínguez Iglesias ${ }^{31}$, que había sido alumno del Instituto de Heidersfield, agregado a la Universidad de Oxford; Antonio Bernárdez, profesor titular de Instrucción Primaria; Manuel Rivera, capitán de Artillería; Cristino Piñeiro, licenciado en Derecho; Vicente Fernández Dios, doctor en Medicina y Cirugía, y Acacio Fraíz, licenciado en Cirugía y Medicina.

En estas circunstancias comenzó el primer y único curso escolar del Instituto en Vigo en este siglo, pues se clausuró antes de comenzar el segundo curso, ya que el Ayuntamiento dejó de satisfacer la subvención convenida correspondiente a los meses de julio,

\footnotetext{
${ }^{26}$ La Concordia (3/10/1873, núm. 45), "Inauguración del Instituto Libre de esta población"

${ }^{27}$ La Concordia (30/06/1874, núm. 122), referente al Instituto de Vigo.

${ }^{28}$ A.M.V., Educación. Leg. 9. Carp.1 Esta carpeta reúne el expediente de fundación del Instituto.

29la Concordia de 30/06/1874. Núm. 122. "Instituto de Vigo". Este profesor fue muy elogiado ya que además de director, se dedicaba también a la Escuela de Comercio, partida doble, lengua inglesa y francesa, dibujo, música, piano y gimnasia.

${ }^{30}$ Fue uno de los fundadores de Faro de Vigo.

${ }^{31}$ Jacobo Domínguez llegó a ser profesor de lenguas en la Universidad de Oxford y en Vigo fue profesor particular de inglés y francés en 1856. Después dio clases en el Liceo de Vigo y en 1879 tenía diversas representaciones: era presidente de la Sociedad Recreativa Casino, presidía la Asociación de Aficionados a la Caza, ostentaba la presidencia de la sociedad de Socorros Mutuos y formaba parte de la Junta local de Primera Enseñanza. En mayo de 1881 ganaba plaza en la Corporación Municipal en la lista de los constitucionales, que con los demócratas constituyeron a finales de junio el nuevo equipo de gobierno, convirtiéndose él en alcalde, el primero de carácter liberal que hubo en Vigo desde el inicio de la Restauración de 1874. Durante su mandato se llevó a cabo la remodelación de la Alameda, la apertura de las calles de Marqués de Valladares y de buena parte de la calle Chao, así como el ensanche de la Campucha. Durante su mandato se inauguró el teatro Rosalía de Castro y además en agosto de 1881 recibió la visita de los Reyes de España. En 1883 confraternizó con Emilio Castelar, que había venido a Vigo a actuar como mantenedor en los Juegos Florales del Recreo Artístico. Abandonó la alcaldía en 1884 y años después se estableció en San Sebastián. Su figura mereció atención en cuanto a las cuestiones educativas por parte de Ángel S. Porto, La Institución Libre de Enseñanza en Galicia (Sada: Ediciós do Castro, 1986), 28 y ss.
} 
agosto y septiembre de 1874 y el Instituto se vio obligado a cerrar ${ }^{32}$, aunque entendemos que influyeron también otros aspectos, debiendo tener en cuenta un decreto del Ministerio de Fomento, en cuya exposición, el ministro Carlos Navarro y Rodrigo decía: "El Gobierno y las Diputaciones o Ayuntamientos pueden fundar Institutos oficiales, pero solo en corto número y en determinadas poblaciones"33. Quizás la tonalidad ideológica aperturista de sus promotores y del Ayuntamiento fuese un motivo más para proceder a su cierre. A pesar de una opinión publicitada sobre la satisfacción ante los resultados.

\section{Nuevas e interminables gestiones}

En $1876^{34}$, dos años después de su cierre, en un artículo de la prensa se expresaba de nuevo la necesidad de la creación del centro en la ciudad:

¿...Por qué no se hace un esfuerzo y desde los hombres filantrópicos hasta las autoridades, desde los que pueden hasta los que deben hacerlo, no se estudia y se plantea un Instituto, una academia, un conservatorio $o$ algo que equivalga a esto, que en definitiva pueda servir a delinear las inteligencias que hoy se malgastan y se pudren sin el pulimento de la instrucción que necesitan?...

Quedaba igualmente patente la necesidad de este establecimiento para la ciudad cuando comenzaba el curso escolar de 1880/188135:

Vigo echa de menos un establecimiento de enseñanza que responda a las necesidades cada día más crecientes de su cultura. Uno de esos centros donde los jóvenes puedan hallar sólida instrucción y tan vasta como lo deseen sus padres. Un colegio que nos evite buscar fuera de aquí lo que hoy no tenemos entre nosotros.

Alguno de los profesores que habían dado clase en él durante su corta existencia, como Telmo Rotea, proponían al Ayuntamiento una solicitud de apertura para un nuevo Colegio de Segunda Enseñanza con una subvención, a cambio de algunas condiciones por parte de la municipalidad, y con la autorización del Gobierno. Sobre la necesidad del Instituto en la ciudad había continuas referencias en la prensa y entre ellas citamos la señalada por Nicolás Taboada Fernández, que expresaba la necesidad también de una Sociedad Económica con clases gratuitas para la gente proletaria y que organizase conferencias públicas ${ }^{36}$ :

\footnotetext{
${ }^{32}$ Con una disposición del Gobierno del 30 de septiembre de 1874, se obligó a suprimir el centro. En La Concordia de 30 de junio podemos comprobar que el instituto seguía abierto en Junio. Queda también constancia administrativa de ello en la conservación de dos expedientes de dos hermanos Casimiro y Juan Gutiérrez y Peraza nacidos en 1859 y 1862 respectivamente; documentos validados por Telmo Rotea secretario del Instituto Libre Vigués. Gerardo González, "Vigo: La difícil conquista de la Enseñanza Media oficial" en Glaucopis: Boletín Instituto de Estudios Vigueses (nº 12, 2006), 171-192.

${ }^{33}$ Gaceta de Madrid de 30/09/1874, Decreto del Ministerio de Fomento de 29 de septiembre de 1874, cit. por Gerardo González, "Vigo: La difícil conquista de la Enseñanza Media oficial" en Glaucopis: Boletín Instituto de Estudios Vigueses ( $\mathrm{n}^{0}$ 12, 2006), 171-192.

${ }^{34}$ Faro de Vigo de 14/11/1876.

${ }^{35}$ La Concordia de 22/09/1880.

${ }^{36} \mathrm{La}$ Concordia de 2/02/1881. Estas conferencias serían dadas por los profesores, creando además un cuadro de profesores honorarios compuesto de personas de reconocida ilustración. Apuntaba también la idea de que las cátedras se proveyesen por oposición, y se formase un tribunal apto dentro o fuera de la ciudad para los exámenes.
} 
...un día cada semana (cómo se hace en las poblaciones cultas) sobre varias materias instructivas tales como historia, literatura, economía política, filología, nociones de derecho, y administración, etc. Que explicadas clara y sencillamente y en forma que deleite y entretenga, habrían de estimular las aficiones adormecidas hoy, no solo de la clase menestral sino de todos los habitantes de nuestro país.

Entre tanto, también es oportuno señalar que en 1884 hubo dos solicitudes para establecer de nuevo en la ciudad el centro; una la suscribió Rosendo Orúe y otra el colegio Santo Tomás de Aquino, dirigido por Telmo Rotea. La primera fue desestimada en favor de la segunda propuesta, aunque ésta nunca llegó tampoco a funcionar como Instituto. El siglo terminó, pues, sin que se lograse fundar el centro, y en los primeros años del siglo XX, Vigo con sesenta mil habitantes y triplicando la población de Pontevedra afirmaba todavía más el derecho a disfrutar de un Instituto público, lo que no se alcanzaría hasta 1927.

\section{7: la creación del Instituto y su posterior instalación definitiva}

En este año la prensa ${ }^{37}$ informó de la Real Orden que concedía a Vigo el tan ansiado Instituto de Segunda Enseñanza. Desde ese día hasta la inauguración del curso, las noticias del Instituto tuvieron presencia constante en las páginas de la prensa. El curso se inauguró oficial y definitivamente el 8 de octubre de 1927 en un solemne acto celebrado en el teatro García Barbón. Asistieron a la ceremonia el rector de la Universidad Compostelana, Blanco Rivero, el alcalde de Vigo Alonso Cuenca, el general gobernador militar Coronel, el comandante de Marina San Juan y el claustro completo del instituto. El curso 1927-1928 comenzó con 189 alumnos matriculados, número que no dejaría de aumentar en los años posteriores ${ }^{38}$.

En 1932 el centro se instalaba tras la disolución de los Jesuitas, en su colegio de Bellavista en la barriada de Teis, haciéndose cargo también del internado y de la enseñanza primaria, donde permaneció hasta 1936. En esta fecha fue desplazado por la autoridad militar, que decidió habilitar el edificio como hospital militar de evacuación de los heridos de la guerra. Sin locales apropiados, la secretaría se instaló provisionalmente en el local de la Escuela de Artes y Oficios, para matricular a los alumnos, y el alcalde Mauro Alonso, dio comienzo a las gestiones de buscar local para el Instituto. Se creó a tal efecto una comisión de padres de familia para colaborar en la localización del mejor emplazamiento y tras visitar varios inmuebles, se optó por emprender la negociación para obtener el pabellón que se había construido recientemente en la finca de los $\mathrm{HH}$. Maristas, en A Areosa. Esta fue su primera ubicación, si bien, la muerte de Irene Cevallos en 1935, hizo posible que el legado de su esposo José Policarpo Sanz ${ }^{39}$ señalado en su testamento de 1888 (un año antes de su muerte en París) destinado, entre otras obras sociales y de acción escolar ${ }^{40} a$

\footnotetext{
${ }^{37}$ Faro de Vigo de 19/06/1927.

${ }^{38}$ Faro de Vigo de 9/10/1927.

${ }^{39}$ Policarpo Sanz hizo su fortuna en la emigración, pues pertenecía a una humilde familia que tuvo que emigrar a América; allí su patrimonio creció de manera considerable por su enlace con Irene Ceballos, hija de un banquero establecido en Nueva York.

${ }^{40}$ Dejó también parte del legado para una escuela de niñas pobres que estaría dirigida por las Hermanas de María y otras a cargo de la elección del Ayuntamiento. Se llamaría escuela del Sagrado Corazón de María. Existe,
} 
un importante colegio o Instituto de educación secundaria, quedase disponible como había dejado escrito en su testamento ${ }^{41}$ para la compra de terrenos y edificación del instituto, aceptando las instrucciones explícitas escritas para su construcción y funcionamiento. Parte del legado era también para la Casa de Caridad y para un hospital en la ciudad.

\section{Dejaba todo su legado a su mujer Doña Irene Cevallos de Sanz, lo que incluía}

....bienes fondos públicos, acciones de ferrocarriles y sociedades, colecciones de cuadros, mobiliario, objetos de arte y demás propiedades de la clase o naturaleza....; "... .muerta mi consorte pasarán todos mis bienes a manos de mis albaceas y tenedores de bienes que sobrevivan muerta ella, que obrarán de mancomún y a un solo efecto para que los administren y atiendan mientras tanto no sean cumplidas por ellos mis disposiciones que serán ejecutadas sin más demora a los seis meses de la fecha del fallecimiento de mi consorte.

En uno de los capítulos hacía referencia a la creación del centro, y comenzaba aconsejando la buena elección de los terrenos:

Elegir y comprar terrenos suficientes para en ellos construir un edificio de cantería a propósito para establecer en él un colegio o Instituto de $1^{\underline{a}}$ y $2^{\underline{a}}$ enseñanza capaz para 2000300 niños o más según sean las necesidades de la población de Vigo y sus alrededores". "El colegio será construido en terrenos fuera del centro de la ciudad que reúnan todas las condiciones higiénicas cerrando en cuadro una verja de hierro y al centro el colegio.

Referente a la administración y admisión de alumnos decía:

No podrá estar bajo ningún concepto bajo la dependencia del Gobierno. La educación será completamente gratuita para todos los niños de las familias pobres de la ciudad que por ningún concepto se pueda exigirles retribución alguna. Si las familias de reconocida posición social lo solicitan pagarán una cuota mensual proporcionada con solo el objeto de contribuir al sustento de la institución.

Señalaba como condición precisa e indispensable (aparece subrayado), la higiene de los niños:

Que todos los niños que asistan al colegio observen el mayor aseo posible. La inspección diaria estará a cargo de un empleado del establecimiento que cuidará de ésta y de las demás atenciones de limpieza en todo el edificio. Al director del colegio recomiendo encarecidamente que se facilite a los vecinos pobres todo medio de asearse antes de entrar en las clases.

Señalaba como debería figurar el nombre en la puerta:

En la parte superior de la entrada principal del colegio se pondrá la inscripción siguiente en letras de bronce: Instituto Santa Irene, consagrado a la Instrucción Pública gratuita fundado por José Policarpo Sanz e Irene Cevallos de Sanz. Año...

Sobre el director y los profesores ${ }^{42}$ señalaba:

El colegio tendrá un director con el cuadro de profesores que sean necesarios y todos ellos, incluso el director, serán nombrados por oposición y al nombrarlos solo se tendrá en cuenta la idoneidad y la buena moralidad y conducta, sin que dominen en la elección influencias personales ni prevenciones políticas de ninguna naturaleza.

a este respecto, una carpeta con el nombre de la fundación que llevaba su nombre: Fundación Policarpo Sanz (1917- 1947). Vid. Archivo Histórico de Pontevedra (en adelante, A. H. P.), Sección Fundaciones. Caja 19.171/3.

${ }^{41}$ A. H. P., Sección Fundaciones. Caja 19.171/3.

${ }^{42}$ lbíd. 


\section{Sobre la adjudicación para la construcción decía:}

Se anunciará por los diarios de la localidad la subasta de la construcción del colegio por espacio de sesenta días y se adjudicará la obra al arquitecto que mejores condiciones presente en gusto de arquitectura, materiales y precio total de la obra.". Respecto al material: "El colegio será dotado de un material de enseñanza nacional o extranjero lo más perfeccionado y práctico que se conozca.

Y sobre la administración que correspondería al Ayuntamiento una vez acabado:

Una vez construido el colegio con todo su material de enseñanza colocado respectivamente en los salones y listo para empezar sus tareas, los albaceas harán entrega del colegio con su mobiliario, capital impuesto y productos a la ciudad de Vigo o al Ayuntamiento en representación de ésta que será propiedad de la ciudad de Vigo. El Ayuntamiento se ocupará de su administración y de velar por los intereses del colegio en general, de cobrar las rentas del capital impuesto para que con ellas sean cubiertas todas las atenciones y necesidades del mismo desde el día en que empiece a funcionar.

La única aplicación del colegio sería la educación:

El colegio no podrá tener otra aplicación que la de educación pública gratuita y confío en que los habitantes de la ciudad de Vigo sabrán defender en todas circunstancias los derechos que adquieren por virtud de la donación que les hago por este testamento.

Sobre su colección de cuadros dejaba establecido que se hiciese un museo en uno de los salones del colegio ${ }^{43}$.

Si al fallecimiento de mi consorte existiera aún mi colección de cuadros compuesta de noventa y cuatro originales y tres copias de maestros antiguos y modernos, como también todos los objetos de arte, porcelanas, relojes, etc. Serán colocados en uno de los salones del colegio Santa Irene que será construido para el objeto y servirá como Museo de Vigo, cuya entrada será libre para los habitantes de la ciudad, forasteros y extranjeros una o dos veces por semana, y fuera de estos días la entrada al museo de Vigo costará una peseta. La entrada será libre para los artistas todos los días que esté abierto el museo, y se le permitirá estudiar los cuadros y sacar copias si lo solicitan del director del museo, que será el presidente del Ayuntamiento de Vigo.

Dejaba estipulado el dinero que se destinaría a cada cometido:

Para establecer el colegio, lego 200.000 pesos oro español, bajo las condiciones estipuladas en los 16 artículos de la cláusula $11^{\underline{a}}$ del presente testamento, cuyos 200.000 pesos se distribuirán del modo siguiente: 130.000 que se impondrán en buenas hipotecas o rentas de Estado europeas, destinando sus réditos exclusivamente al sostenimiento del colegio. 50.000 pesos para la compra de terrenos y costo de construcción del colegio. 20.000 pesos para la compra de material de primera y segunda enseñanza, que será de lo más perfeccionado y práctico que usan los colegios de esta clase en Europa.

Durante la posterior presidencia de alcaldía de Luis Suárez Llanos, se indica en las actas municipales ${ }^{44}$ que Manufactures Trust Company de Nueva York había remitido al Ayuntamiento un cheque por valor de 207.136,01 dólares, importe del capital legado a la ciudad de Vigo. Asimismo llegaron en el vapor "Artigas" procedentes de Nueva York cinco cajones conteniendo cuadros y objetos artísticos con destino al Museo Municipal. A partir de entonces se anunció en la prensa de la localidad durante sesenta días el concurso de arquitectos para la presentación de proyectos de un edificio de cantería con destino a colegio de Primera y Segunda Enseñanza. Finalmente, en marzo de 1941 la corporación

${ }^{43}$ Ibíd.

${ }^{44}$ Actas del Pleno del Ayuntamiento de Vigo con fecha de 16/01/1941. 
municipal asumió la cesión de la parcela de "El Carmen", magnífico solar de 60.000 metros cuadrados situado en uno de los lugares de mayor porvenir de la ciudad para iniciar la construcción del Instituto. El arquitecto Antonio Cominges Tapias sería el encargado de diseñar el proyecto.

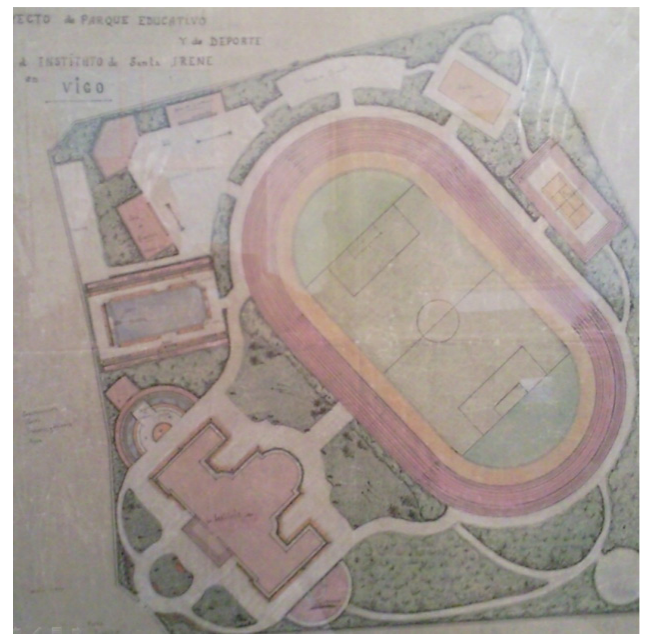

Proyecto del instituto ${ }^{45}$.

Se trataba de un edificio en forma de E toda el de cantería, que buscaba una buena iluminación y ventilación del interior. La fachada principal seguía un esquema ecléctico. El 30 de junio ${ }^{46}$ se celebró un pleno extraordinario para tratar el proyecto de construcción del Instituto y a continuación se sacó a subasta la adjudicación de las obras, dadas a la casa Pérez Conde ${ }^{47}$ y se comenzó su construcción.

Las obras finalizaron en marzo de $1946^{48}$. El Instituto Santa Irene fue inaugurado oficialmente el 16 de septiembre de ese mismo año en un acto celebrado en el paraninfo del centro. Era un gran edificio para la época y aún lo sigue siendo; la ornamentación se centraba en el cuerpo central destacado con una poderosa torre que actuaba como elemento emblemático y referencial. Este edificio se dotaba con magníficas instalaciones, como el laboratorio, gimnasio, biblioteca, capilla, cantina, paraninfo, zona deportiva, y hasta cine sonoro. Sus instalaciones serían consideradas en su época entre las mejores de España. La primera y la segunda planta están compuestas por una sucesión de columnas dobles de estilo jónico. En el acceso principal hay un amplio pórtico sobre el que se sitúa una terraza ornamentada con una balaustrada de estilo neobarroco. En los tramos laterales

\footnotetext{
$\overline{45}$ Imagen tomada el día 10/10/2013 de la web Vigopedia: $h$ ttp://vigopedia.com/cronologia-de-vigo-siglo$x x /$

${ }^{46}$ Actas del Pleno del Ayuntamiento de Vigo con fecha de 30/06/1941

${ }^{47}$ Faro de Vigo de 5/09/1945.

${ }^{48}$ Faro de Vigo de $7 / 09 / 1946$.
} 
se localizan unas pilastras que delimitan una sucesión ordenada de vanos. Destaca el tratamiento de la cantería. En la construcción se utilizó granito blanco de Ulló (Arcade).

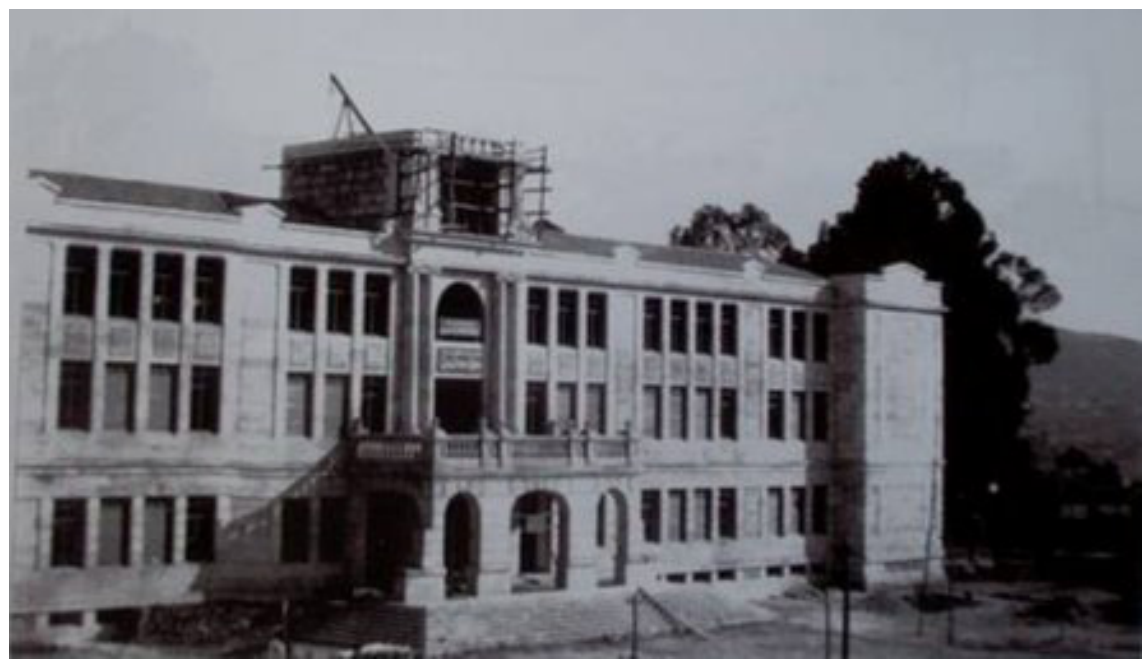

El instituto en construcción ${ }^{49}$.

La distribución del inmueble se hizo siguiendo las más modernas orientaciones para aquella época: así, la parte administrativa, antesala del público, oficinas, despachos del director, secretario e interventor, tienen directo acceso desde el exterior. Igual sucede con el paraninfo, la capilla y el teatro. En la misma planta baja se halla situado el comedor. Finalmente existe también una espléndida sala de gimnasia, con sus vestuarios y sus duchas. En las restantes plantas se hallan distribuidas 18 aulas, con una capacidad total para 1400 alumnos. Cada una de ellas, de conformidad con las normas pedagógicas vigentes en el momento, tenían cabida para 44 alumnos, iluminación exclusivamente por la izquierda, ventanales que permiten la cantidad necesaria de luz natural y una altura de techos calculada para que cada alumno disfrute del mayor número posible de metros cúbicos de aire. En cuanto al mobiliario fue elegido científicamente ${ }^{50}$.

El centro posee un amplio salón de dibujo, orientado al norte, donde, además de poder desarrollar esta disciplina, los alumnos podían aprender los trabajos manuales de vaciado y modelado, ebanistería, etc. También cuenta con biblioteca y laboratorios de Física, Química e Historia Natural, además de un magnífico museo de esta última especialidad.

\footnotetext{
${ }^{49}$ Imagen capturada el día 10/10/2012 de la web: http://vellaenobregallaecia.blogspot.com.es/2008/07/vigoconstrucin-do-instituto-santa.html

${ }^{50}$ Información capturada el día 10/10/2012 de la web: http://arquitecturavigo.blogspot.com.es/2008/10/institutosanta-irene.html.
} 


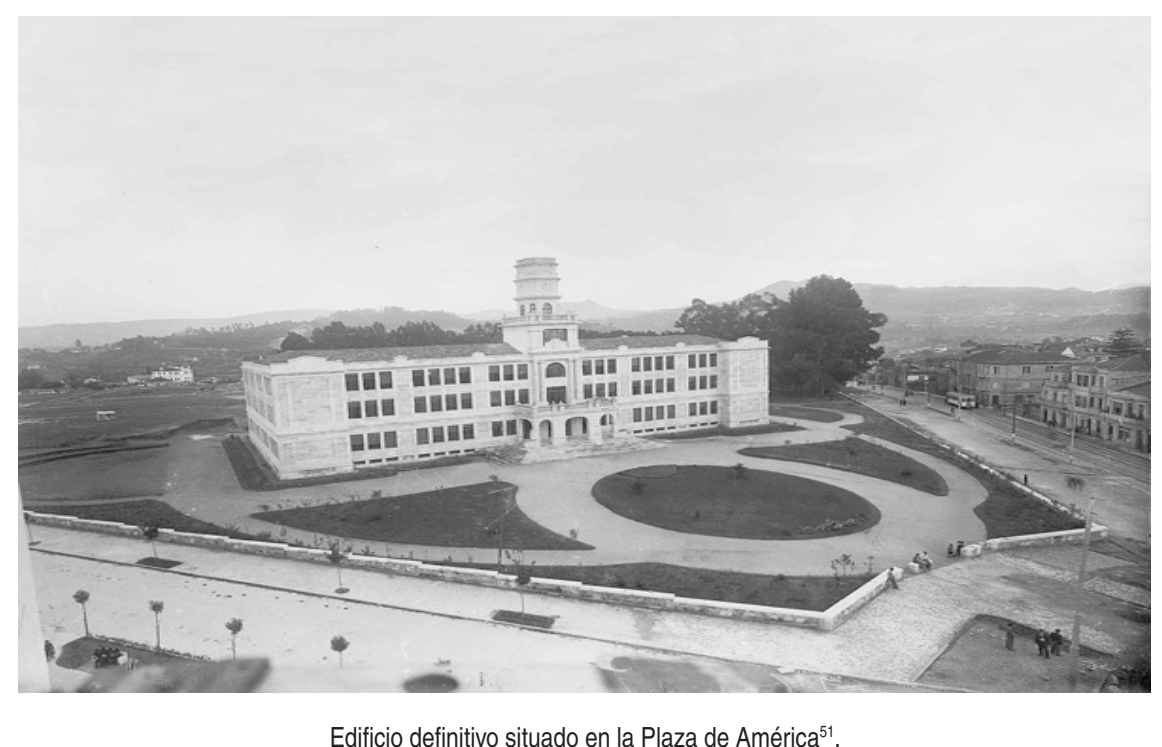

Además, en 1946 se estaba a la espera de que se concediera un crédito ministerial para acometer los trabajos de la zona deportiva en la parte posterior del edificio. Dicha zona comprendería un campo de futbol de dimensiones olímpicas, con un graderío para 2500 personas y una tribuna presidencial; una pista de ceniza para carreras; un frontón de 16 cuadros, con una grada para 500 personas; una pista para saltos de longitud y de altura, lanzamiento de jabalina, disco y martillo; dos pistas de tenis, campo de croquet, campo de baloncesto; una gran pista de patinaje de 40 metros de radio; aulas al aire libre, cubiertas, y un campo para gimnasia rítmica.

Este nuevo edificio comenzó pues a funcionar el curso 1945-1946 bajo la dirección del profesor López Niño, que también era concejal, impartiéndose clases y todo tipo de actividades, con arreglo al siguiente plan: los alumnos se trasladaban al centro en tranvías especiales, bajo la vigilancia de personal adecuado; las horas de estancia eran de nueve y media de la mañana a una de la tarde; y de cuatro a seis y media de la tarde. No coincidían jamás en ningún servicio las alumnas con los alumnos. La dirección y jefatura de estudios comunicaba mensualmente a los padres la asistencia a clase de éstos, sus comportamientos, etc. Para casos imprevistos existían profesores de guardia permanente a quienes podía solicitarse, personalmente o por teléfono, cualquier información relacionada con los estudiantes.

El 6 de septiembre de 1946, cuando el ministro de Educación y Ciencia Ibáñez Martín realizaba una gira por Galicia, presidió la ceremonia inaugural de Santa Irene con la presencia de las más altas jerarquías civil, militar, eclesiástica y académica. Recorrió todas las dependencias del instituto, mostrándose muy satisfecho de cada una de las instalaciones,

\footnotetext{
${ }^{51}$ Imagen capturada el día 10/10/2012 de la web: http://vigopedia.com/cronologia-de-vigo-siglo-xx/
} 
confirmando así la magnífica impresión que tenía del nuevo centro decente, a través de las fotografías que le había presentado en Madrid el director López Niño, a la vista de las cuales había manifestado que el instituto de Vigo era de los mejores de España ${ }^{52}$. Lo bendijo el obispo José López Ortíz. En su intervención, el alcalde recordó que había tenido el honor de ocupar la alcaldía, "cuando la ciudad de Vigo recibió este legado en 1941, 54 años después del testamento y 47 del fallecimiento del donante"53. En el mismo acto, el miembro del Gobierno impuso a Luis Suárez Llanos las insignias de la Orden de Alfonso $X$ el Sabio. Ya en el paraninfo del Instituto, el rector de la Universidad de Santiago daba la primera lección magistral, antes de que Suárez Llanos recordara el largo camino transcurrido desde el fallecimiento de Policarpo Sanz.

El edificio se conserva actualmente y sigue siendo sede activa del Instituto de Bachillerato más antiguo de la ciudad.

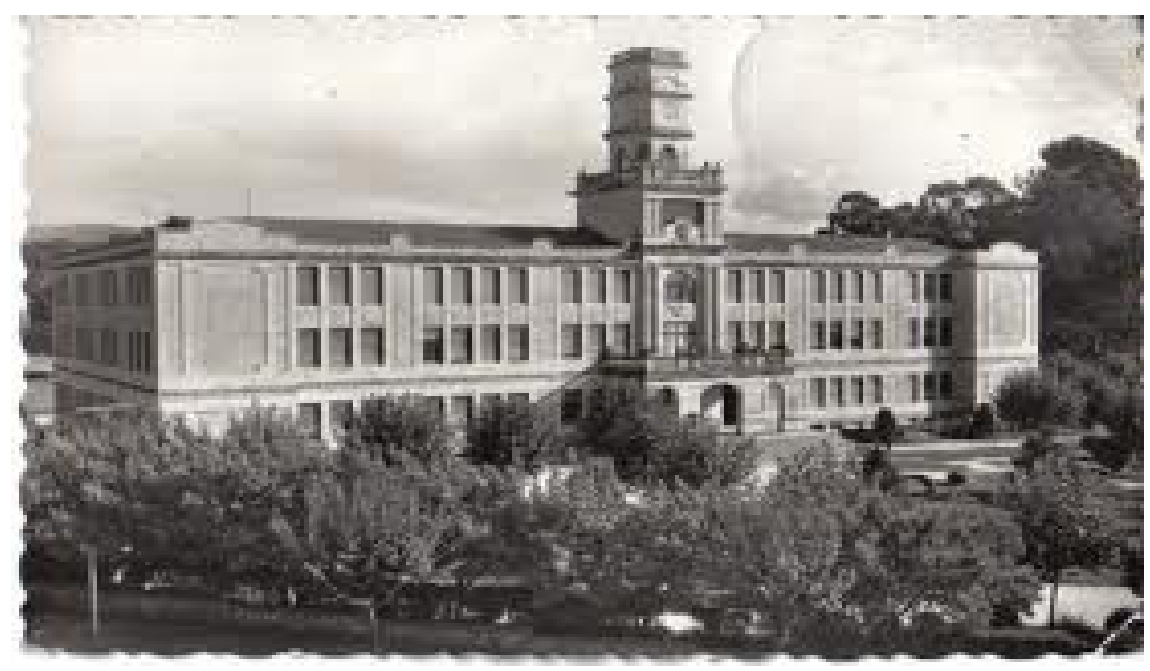

Instituto Santa Irene ${ }^{54}$

${ }^{52}$ Faro de Vigo de 7/07/1946.

${ }^{53}$ Gerardo González, "Vigo: La difícil conquista de la Enseñanza Media oficial” en Glaucopis: Boletín Instituto de Estudios Vigueses ( $\left.\mathrm{n}^{\circ}-12,2006\right), 171-192$.

${ }^{54}$ Imagen capturada el día 10/10/2013 de la web: http://clasica2.com/?_=/clasica/Hemeroteca-de-Musica-Clasica/ Festival-Artistico-Instituto-Santa-Irene-de-Vigo-Curso-1954-1955 